\title{
Regulation of FOXP3 Expression in Blood Cells in Response to All-Trans-Retinoic Acid, Interleukin 2 and Transforming Growth Factor $\beta$
}

\author{
Aleksandra Ilnicka1,2, Elżbieta Gocek ${ }^{1,3}$, Justyna Lopatecka1,4 and Ewa Marcinkowska ${ }^{1, *}$ \\ 1 Department of Biotechnology, University of Wrocław, Joliot-Curie 14a, 50-383 Wrocław, Poland; \\ ema@cs.uni.wroc.pl \\ 2 Current address: NZOZ Aurimed, Piwna 13, 50-353 Wrocław, Poland; aleksandrailnicka94@gmail.com \\ 3 Current address: Polish Center for Technology Development, Stabłowicka 147, 54-066 Wrocław, Poland; \\ elzbieta.gocek@port.org.pl \\ 4 Current address: School of Biomedical and Healthcare Sciences, Peninsula Schools of Medicine and \\ Dentistry, Plymouth University, Plymouth, United Kingdom; justyna.lopatecka@plymouth.ac.uk \\ * Correspondence: ema@cs.uni.wroc.pl; Tel.: +48-71-375-2929
}

\begin{abstract}
FoxP3 is a transcription factor essential for the differentiation and function of $\mathrm{T}$ regulatory cells (Tregs). There are two major subsets of Tregs: natural Tregs (nTregs) generated in thymus and inducible Tregs (iTregs) produced in peripheral immune system. It has been documented that iTreg development is dependent on soluble mediators including interleukin 2 (IL2), transforming growth factor $\beta$ (TGF $\beta$ ) and all-trans-retinoic acid (ATRA). In our experiments we performed a gene expression array, followed by Real-time PCR experiments, to study the expression of genes regulated by 1,25 -dihydroxyvitamin $\mathrm{D}(1,25 \mathrm{D})$ or ATRA in cells of myeloid origin. Our experiments revealed that ATRA alone, but also a cocktail of mediators consisting of IL2, TGF $\beta$ and ATRA, upregulate the expression of FOXP3 gene in lymphoid cells, but also in normal and leukemic myeloid cells. The FoxP3 expression is followed by a phenotypic changes in cells of myeloid origin. Our results indicate that signaling pathways which are used in the late stages of $\mathrm{T}$ cell differentiation, are also active in the cells of myeloid lineage.
\end{abstract}

Keywords: blood cells; differentiation; myeloid leukemia; monocytes; lymphocytes; transcription factors; all-trans-retinoic acid; interleukin 2; transforming growth factor $\beta$

\section{Introduction}

Blood cells develop in bone marrow in a process called hematopoiesis. All blood cells originate from multipotent hematopoietic stem cells (HSCs) which after division generate daughter stem cells and pluripotent progenitor cells [1]. According to the branching tree model of hematopoiesis, there are two types of pluripotent progenitors, common lymphoid progenitors (CLPs) which give rise to natural killers (NK), B and T cells, and common myeloid progenitors (CMPs) which further differentiate into platelets, erythrocytes, granulocytes, monocytes and mast cells. However, dendritic cells (DCs) do not fit this branching model, since they might be generated via either the myeloid or lymphoid pathways. Whether these two pathways generate two separate subsets of DCs, or identical DCs are produced by two flexible and interchangeable routes, is a matter of dispute [2]. Moreover, the experiments have revealed that progenitors of B cells and monocytes [3, 4], as well as those of $T$ cells and monocytes, are closely related $[5,6]$. These data indicate that a sharp distinction between lymphoid and myeloid differentiation pathways does not exist [7]. Therefore a pairwise relationships model of hematopoiesis has been proposed according to which HSCs can reach a specific cell fate through more than one type of intermediate progenitors [8].

Our research group has been interested in the subject of differentiation therapy for myeloid leukemia for many years $[9,10]$. The paradigmatic, and the most successful form of differentiation therapy, is the one in which all-trans-retinoic acid (ATRA) is used to treat acute promyelocytic 
leukemia [11]. ATRA, and other metabolites of retinoic acid, are the ligands for nuclear retinoic acid receptors (RARs) which act as ligand-activated transcription factors. Similarly, the hormonal form of vitamin $\mathrm{D}, 1,25$-dihydroxyvitamin $\mathrm{D}(1,25 \mathrm{D})$, is an activating ligand for vitamin $\mathrm{D}$ receptor (VDR) [12]. RARs and VDR are present in blood cells at various steps of hematopoiesis, and are particularly active in early stages [13]. Both types of receptors are also present and active in blast cells from many, but not all, patients with acute myeloid leukemia (AML) [14, 15]. The most studied model of AML, capable of responding to ligands of VDR and RARs, is HL60 cell line [16]. These cells can be differentiated into either neutrophils or monocytes [17]. For our research, we performed a screening of expression of over 90 genes connected with blood differentiation in HL60 cells exposed to ATRA or to 1,25D. The genes studied were either related to the function of neutrophils or monocytes, or coded transcription factors which take part in hematopoiesis. We also tested genes, which are considered housekeeping, such as $18 S$ rRNA or ACTB. Our screening revealed 12 genes upregulated and 3 downregulated in response to 1,25D. The most strongly upregulated one was CYP24A1, which constituted a positive control in our screening [18]. We also found 12 genes upregulated and 2 downregulated in response to ATRA. One of the genes significantly upregulated in response to ATRA in HL60 cells was FOXP3, encoding a transcription factor forkhead box P3 (FoxP3), which is a master regulator of regulatory T cells (Tregs) [19]. Therefore, in this study, we decided to address the regulation of this gene in cells of myeloid lineage.

\section{Results}

2.1. Expression of wide array of genes connected with blood differentiation in HL60 cells exposed to $1,25 D$ or to ATRA

In order to study a wide array of genes regulated in response to 1,25D or to ATRA, we decided to take advantage of customized RT2 Profiler ${ }^{\mathrm{TM}}$ PCR Array from Qiagen. We selected genes important for the function of neutrophils and monocytes along with transcription factors characteristic for hematopoiesis. Such array contained also internal controls and housekeeping genes which were used as a reference. In our assay, the expression of CYP4A1 in HL60 cells exposed to 1,25D was an internal control. It has been documented that this gene is the one most strongly regulated by $1,25 \mathrm{D}$ [18]. From our previous research, we have known that in HL60 cells the kinetics of upregulation of CYP24A1, encoding 24-hydroxylase of 1,25D, is slow [20]. Thus we decided to expose the cells to 1,25D or ATRA for 96 hours. $18 S$ rRNA was used as a reference gene. The full list of genes studied and their expression levels are presented in Table A1 (Appendix A). We found that exposure of HL60 cells to 1,25D significantly upregulated 12 genes and downregulated 3. In parallel, an exposure of HL60 cells to ATRA significantly upregulated 12 genes, while downregulated 2 . All genes whose expression was significantly $(\mathrm{p}<0.05)$ changed in response to the treatment are presented in Figure 1.

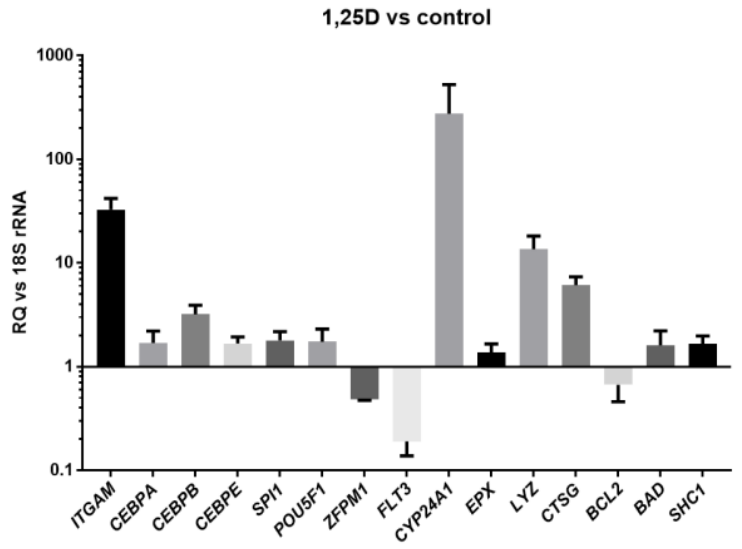

(a)

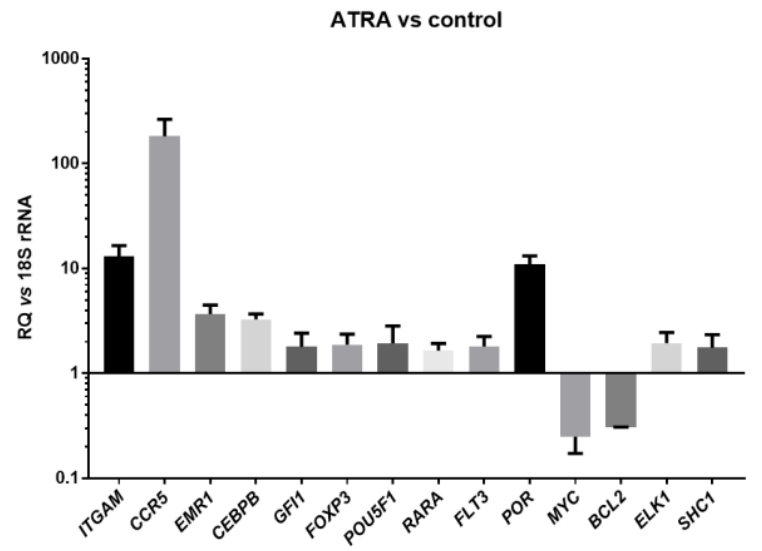

(b)

Figure 1. Analysis of gene expression induced by 1,25D or ATRA in HL60 cells. The cells were exposed to vehicle control, to $10 \mathrm{nM}$ 1,25D or to $1 \mu \mathrm{M}$ ATRA for 96 hours. Then the expression of 93 
genes was studied using RT2 Profiler ${ }^{\mathrm{TM}}$ PCR Array. 18S rRNA was used as a reference gene and untreated cells were used as a calibrator. Genes whose expression was significantly changed in response to $10 \mathrm{nM}$ 1,25D are presented in panel (a), while those whose expression was significantly changed in response to $1 \mu \mathrm{M}$ ATRA are presented in panel (b). P-values are presented in Table A1.

As expected CYP24A1 was the most strongly upregulated gene in response to 1,25D (more than 200 times). The gene most strongly upregulated in response to ATRA was CCR5, which encodes a chemokine receptor. Then we had to decide, which genes should be investigated in more details, in order to confirm or deny their regulation by 1,25D or ATRA. In our subsequent work, we performed more exhausting studies to verify the results obtained. In our first attempt, we verified that indeed POR gene, encoding for NADPH-cytochrome P450 oxidoreductase (POR), is regulated by ATRA in AML cell lines, in normal blood leukocytes and in AML blasts from patients [21]. POR is an electron donor for all microsomal CYP enzymes and is important for catabolism of ATRA. Later, we have tested in great details regulation of transcription factors from CCAAT/enhancer-binding protein (C/EBP) family, which are key regulators of the development and function of the myeloid system [22]. Expression of CEBPA, CEBPB, CEBPG and CEBPE in AML cells appeared to be variably regulated in cells with variable levels of RAR $\alpha$ and VDR proteins [23]. We did not investigate further the regulation of genes, which are important for the function of granulocytes or monocytes, such as IGTAM, which encodes adhesion molecule CD11b [24] or LYZ encoding lysozyme [25], because their regulation by either $1,25 \mathrm{D}$ or ATRA was expected. At this step of our research, we decided to investigate the regulation of FOXP3 expression in response to ATRA.

\subsection{Regulation of FOXP3 in Jurkat cells in response to ATRA}

The cells most expected to upregulate FOXP3 gene are the ones of lymphoid origin. Since normal $\mathrm{T}$ cells are hard to obtain in high numbers, we decided to use Jurkat cell line as a model to study FOXP3 upregulation. Jurkat cells are immortalized human $\mathrm{T}$ lymphocytes, often used to study $\mathrm{T}$ cell signaling [26]. In these cells, constitutive expression of FOXP3 gene is low, but can be upregulated in response to hepatitis $C$ virus infection [27]. At first, we decided to examine the kinetics of FOXP3 regulation in response to ATRA in Jurkat cells. Therefore these cells were exposed to $1 \mu$ M ATRA for 24, 48 and 96 hours, and then the expression of FOXP3 was tested in Real-time PCR using glyceraldehyde 3-phosphate dehydrogenase $(G A P D H)$ gene as a reference. The results presented in Figure 2 show that upregulation of FOXP3 in response to ATRA in Jurkat cells was moderate and slow. Significant upregulation was observed only after 96 hours of treatment, and the mean value of upregulation was 1.76 .

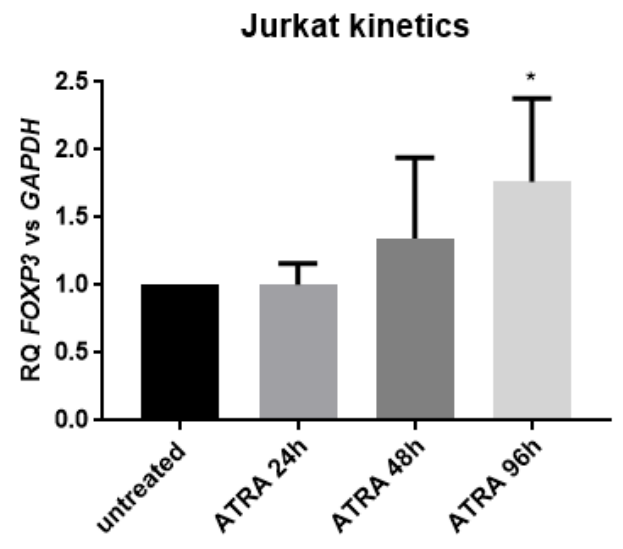

Figure 2. Kinetics of FOXP3 gene expression in response to ATRA in Jurkat cells. The cells were exposed to $1 \mu \mathrm{M}$ ATRA and after the desired time the expression of FOXP3 gene was measured by Real-time PCR. The bars represent mean values ( \pm standard error of the mean (SEM)) of the fold changes in mRNA levels relative to glyceraldehyde 3-phosphate dehydrogenase (GAPDH) mRNA 
levels. Expression in control cells (exposed to the vehicle) was used as a calibrator. The value significantly different from that observed in control cells is marked with an asterisk $\left({ }^{*} \mathrm{p}<0.05\right)$.

\subsection{Regulation of FOXP3 in Jurkat cells in response to ATRA, IL2 and TGF $\beta$}

Since the upregulation of FOXP3 expression in Jurkat cells in response to ATRA alone was only moderate, we decided to find a more effective procedure. An efficient protocol of the generation of regulatory cells from naïve T CD4 cells has been reported using ATRA, interleukin 2 (IL2) and transforming growth factor $\beta$ (TGF $\beta$ ) [28]. In the original protocol, naïve T cells were exposed to 100 $\mathrm{IU} / \mathrm{ml}$ (equivalent to $10 \mathrm{ng} / \mathrm{ml}$ ) IL2, $5 \mathrm{ng} / \mathrm{ml}$ TGF $\beta$ and $10 \mathrm{nM}$ ATRA for 6 days. Such treatment did not result in upregulation of FOXP3 in Jurkat cells, thus we decided to increase the concentration of ATRA to $1 \mu \mathrm{M}$, and to shorten the exposure time to 96 hours. In our experiments Jurkat cells were exposed to $10 \mathrm{ng} / \mathrm{ml}$ IL2, $5 \mathrm{ng} / \mathrm{ml}$ TGF $\beta$ or $1 \mu \mathrm{M}$ ATRA alone, or in combination, and then the expression of FOXP3 gene was tested in Real-time PCR using GAPDH as a reference. As presented in Figure 3, $1 \mu \mathrm{M}$ ATRA upregulated expression of FOXP3 gene similarly to the previous experiment (1.52 times), however with higher statistical significance ( $p=0.02$ ). IL2 alone slightly downregulated, TGF $\beta$ slightly upregulated it, while a combination of all three compounds significantly upregulated expression of FOXP3 (2.14 times).

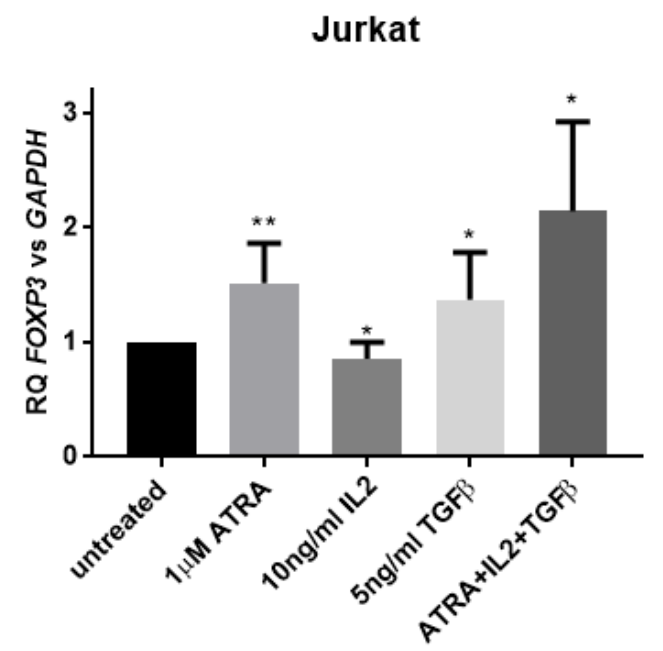

Figure 3. Expression of FOXP3 gene in Jurkat cells exposed to ATRA, IL2 and TGF $\beta$. The cells were exposed to $1 \mu \mathrm{M}$ ATRA, $10 \mathrm{ng} / \mathrm{ml}$ IL2, $5 \mathrm{ng} / \mathrm{ml}$ TGF $\beta$ alone or in combination and after 96 hours the expression of FOXP3 gene was measured by Real-time PCR. The bars represent mean values ( \pm SEM) of the fold changes in mRNA levels relative to GAPDH mRNA levels. Expression in control cells (exposed to the vehicle) was used as a calibrator. The values significantly different from that observed in control cells are marked with asterisks $\left(^{*} \mathrm{p}<0.05,{ }^{* *} \mathrm{p}<0.01\right)$.

\subsection{Regulation of FOXP3 in HL60 cells in response to ATRA, IL2 and TGF $\beta$}

We decided to perform the same scheme of experiment in HL60 cells. The treatment protocol was identical to that with Jurkat cells, and the results are presented in Figure 4. In HL60 cells exposed to $1 \mu \mathrm{M}$ ATRA, the expression of FOXP3 was significantly upregulated (1.81 times), and the result was similar to the one obtained in gene expression array (1.7648 times), even though the reference gene was different. In HL60 cells exposed to either $10 \mathrm{ng} / \mathrm{ml}$ of IL2 or $5 \mathrm{ng} / \mathrm{ml}$ of TGF $\beta$, the expression of FOXP3 was significantly downregulated (0.66 times and 0.62 times respectively). When HL60 cells were exposed to all three compounds in combination, the expression of FOXP3 was upregulated 4.48 times, which was more than in Jurkat cells. 


\section{HL60}

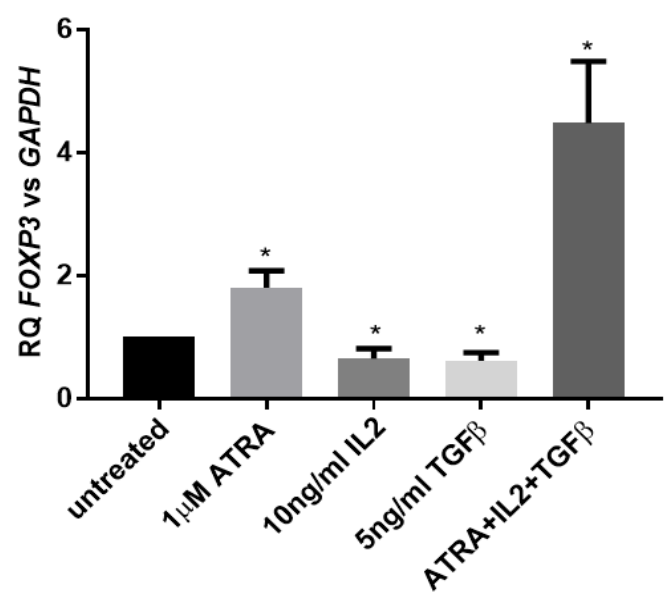

Figure 4. Expression of FOXP3 gene in HL60 cells exposed to ATRA, IL2 and TGF $\beta$. The cells were exposed to $1 \mu \mathrm{M}$ ATRA, $10 \mathrm{ng} / \mathrm{ml}$ IL2 and $5 \mathrm{ng} / \mathrm{ml}$ TGF $\beta$ and after 96 hours the expression of FOXP3 gene was measured by Real-time PCR. The bars represent mean values ( \pm SEM) of the fold changes in mRNA levels relative to GAPDH mRNA levels. Expression in control cells (exposed to the vehicle) was used as a calibrator. The values significantly different from that observed in control cells are marked with asterisks $\left({ }^{*} \mathrm{p}<0.05\right)$.

\subsection{Phenotype of Jurkat and HL60 cells after exposure to ATRA alone or in combination with IL2 and TGF $\beta$}

In order to examine if the expression of FOXP3 was accompanied by changes in cell phenotype we tested Jurkat and HL60 cells, either untreated or exposed for 96 hours to $1 \mu \mathrm{M}$ ATRA alone or in combination with $10 \mathrm{ng} / \mathrm{ml}$ IL2 and $5 \mathrm{ng} / \mathrm{ml} \mathrm{TGF} \beta$, in flow cytometry. Jurkat cells were labelled using anti-CD3, anti-CD4 and anti-CD25, while HL60 cells using anti-CD11b, anti-CD4 and anti-CD25 antibodies. CD3 and CD4 are cell surface receptors characteristic for helper T cells, while CD25 is abundant in Tregs [29]. The results presented in Figure 5 indicate that the expression of CD25 was stable and did not change in either of the cell lines. In Jurkat cells some, but not significant decrease in the expression of CD3 and CD4 was observed (Figure 5a). In HL60 cells a significant increase of CD11b was observed after both treatments, and this result was expected, since ATRA-induced granulocytic differentiation was reported in the past [17]. As presented in Figure 5b, combination treatment induced significant increase of CD4 antigen in HL60 cells.

Jurkat

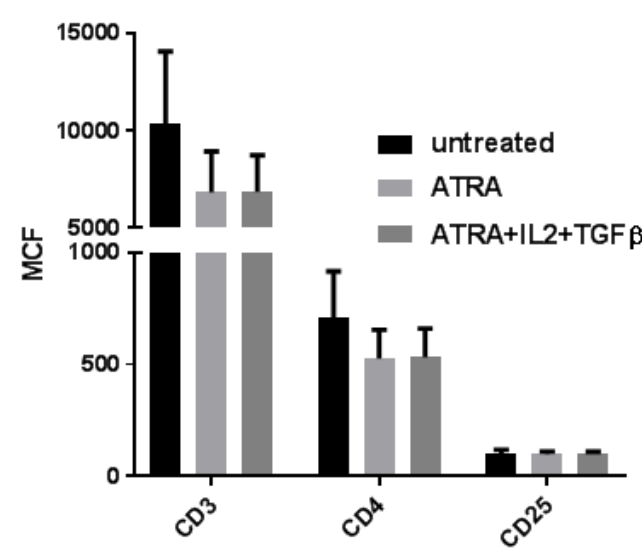

(a)

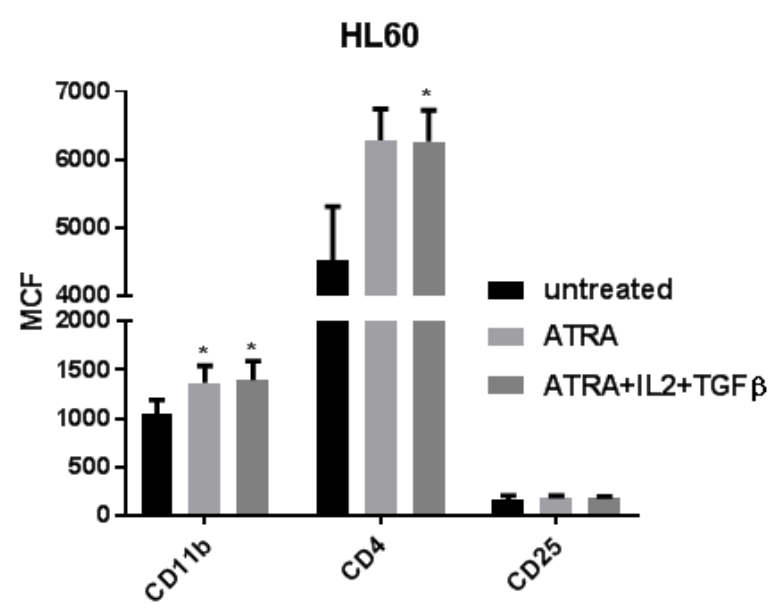

(b)

Figure 5. Phenotype of Jurkat (a) and HL60 (b) cells untreated or treated with ATRA alone or in combination with IL2 and TGF $\beta$. The cells were left untreated or exposed to $1 \mu \mathrm{M}$ ATRA alone, or in 
combination with $10 \mathrm{ng} / \mathrm{ml}$ IL2 and $5 \mathrm{ng} / \mathrm{ml}$ TGF $\beta$ for 96 hours. Afterwards, the expression of CD11b, CD4, CD3 and CD25 on the cell surface was studied using flow cytometry. Mean channels of fluorescence $(\mathrm{MCF})$ of studied antigens are presented. The values significantly different from that observed in respective untreated cells are marked with asterisks $\left({ }^{*} \mathrm{p}<0.05\right)$.

\subsection{Regulation of FOXP3 in normal myeloid cells in response to ATRA, IL2 and TGF $\beta$}

HL60 cells originate from AML and carry numerous mutations. Thus we wanted to verify, whether the ability to upregulate FOXP3 in response to ATRA, IL2 and TGF $\beta$ is a feature of myeloid neoplasms or of myeloid cells in general. We decided to use umbilical cord blood (UCB) as a source of monocytes. Our first attempt was to isolate monocytes using magnetic MicroBeads, against human CD14, from Miltenyi Biotec (Bergisch Gladbach, Germany). Unfortunately, despite in this procedure pure populations of monocytes were isolated, the cells after the procedure were not in numbers enough for further culture. As an alternative, we decided to take advantage of the protocol, in which monocytes are separated from lymphocytes by adherence to the surface [31]. We were aware that such population is only enriched in monocytes, thus we tested the population of mononuclear cells before and after adhesion in flow cytometry. The cells were labeled with anti-CD11b conjugated to FITC and anti-CD14 conjugated to PE antibodies. Controls labeled with isotype matched immunoglobulins, conjugated to both fluorochromes were also tested. Our experiments, presented in Figure 6a, revealed that the population of adherent cells was significantly enriched in monocytes, in comparison to unsorted or to non-adherent UCB cells. Populations of monocytes with intermediate expression of CD14, as well as monocytes with high expression of CD14 were enriched by the adhesion to the surface (Figure $6 \mathrm{~b}-\mathrm{d}$ )

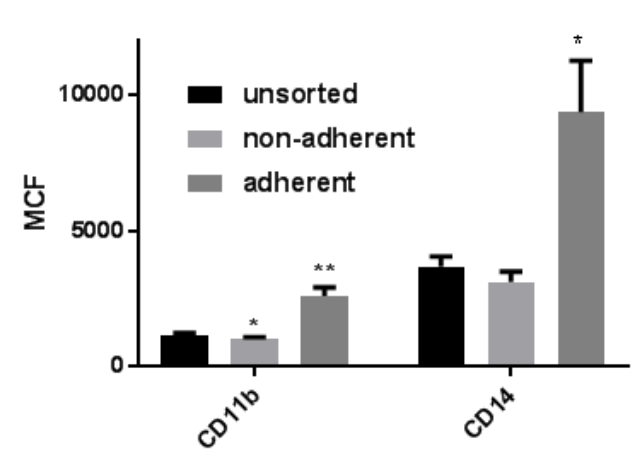

(a)

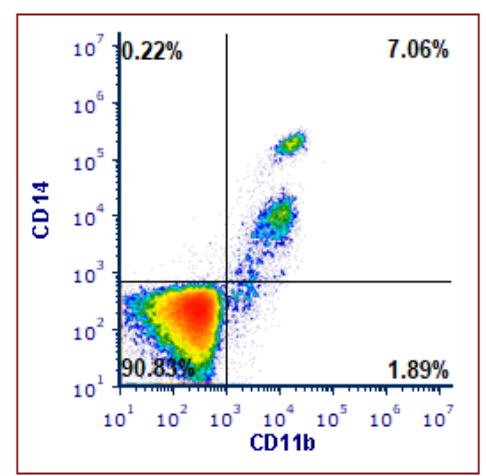

(c)

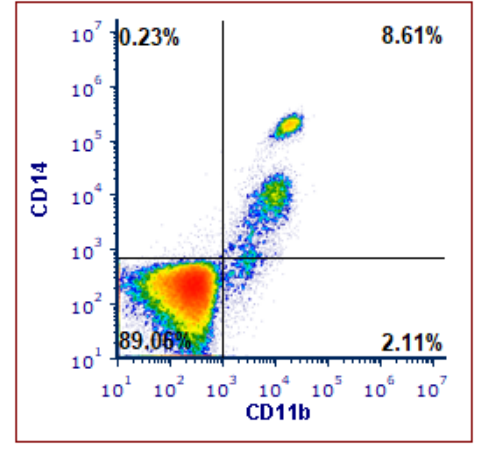

(b)

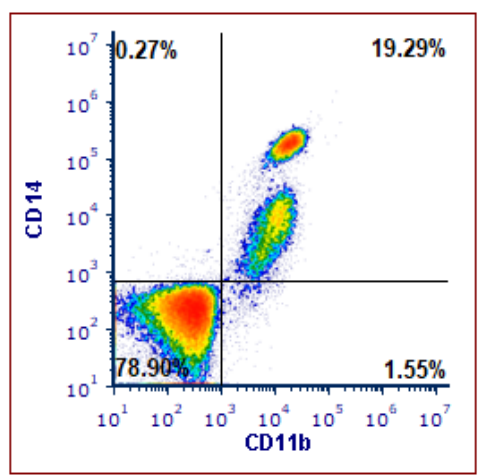

(d)

Figure 6. Expression of monocyte antigens on adherent mononuclear cells. Mononuclear cells from UCB unsorted, non-adherent and after enrichment using adhesive properties (adherent) were labeled with anti-CD11b conjugated to FITC and anti-CD14 conjugated to PE. Mean channels of fluorescence (MCF) of both antigens are presented in panel (a). The values significantly different from these observed in unsorted cells are marked with asterisks $\left({ }^{*} \mathrm{p}<0.05,{ }^{* *} \mathrm{p}<0.01\right)$. Representative dot-plots 
showing expression of CD11b and CD14 on unsorted (b), non-adherent (c) and adherent (d) cells are presented.

Although the population of adherent mononuclear cells contained not only monocytes, we decided to test how would they react to the exposure to ATRA, IL2 and TGF $\beta$. Since the number of adherent cells was limited, only two types of exposure were applied in this series of experiments: vehicle versus ATRA, IL2 and TGF $\beta$ in combination. Expression of FOXP3 in unsorted and in adherent mononuclear cells from UCB was tested and the results are presented in Figure 7 . The expression of FOXP3 was downregulated ( 0.55 times) in unsorted cells, while it was moderately (1.32 times), but significantly upregulated in adherent cells exposed to ATRA, IL2 and TGF $\beta$, when compared to untreated cells.

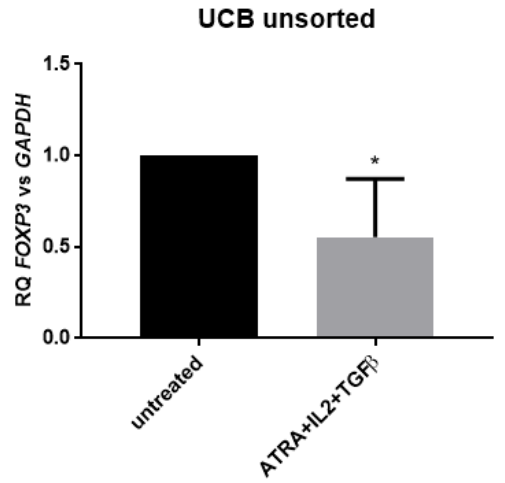

(a)

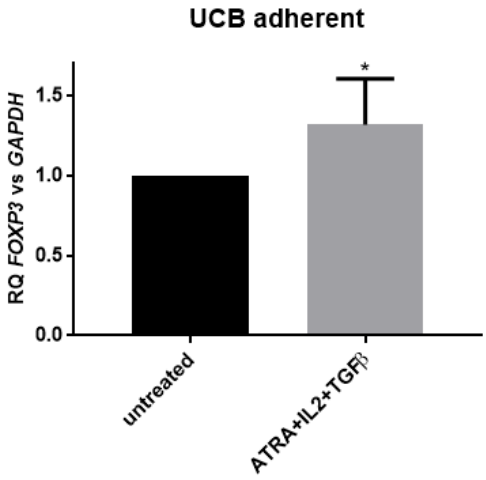

(b)

Figure 7. Expression of FOXP3 gene in mononuclear cells from UCB exposed to ATRA, IL2 and TGF $\beta$. Unsorted (a) or adherent (b) cells from UCB were left untreated or exposed to $1 \mu \mathrm{M}$ ATRA, $10 \mathrm{ng} / \mathrm{ml}$ IL2 and $5 \mathrm{ng} / \mathrm{ml}$ TGF $\beta$, and after 48 hours the expression of FOXP3 gene was measured by Real-time PCR. The bars represent mean values $( \pm$ SEM) of the fold changes in mRNA levels relative to GAPDH mRNA levels. Expression in control cells (exposed to the vehicle) was used as a calibrator. The values significantly different from these observed in respective control cells are marked with asterisks ${ }^{*} \mathrm{p}<$ 0.05).

In the next series of experiments we wanted to test, if the phenotype of adherent UCB cells was different after exposure to ATRA, IL2 and TGF $\beta$ from control cells. We tested expression of CD4, but there were no significant differences after exposure (not shown). Thus, we hypothesized that the cocktail of above soluble mediators might trigger differentiation of monocytes towards tumor-associated phenotype. In order to verify this hypothesis, expression of CD163 and CD206 was tested in adherent UCB cells, untreated or exposed for 48 hours to 1 $\mu \mathrm{M}$ ATRA, $10 \mathrm{ng} / \mathrm{ml}$ IL2 and $5 \mathrm{ng} / \mathrm{ml}$ TGF $\beta$. CD163 is a hemoglobin-haptoglobin scavenger receptor, while CD206 is a C-type mannose receptor 1, and both receptors have been reported to be present on tumor-associated macrophages [32]. Our experiments revealed that expression of CD163 was reduced, but not significantly in the cells tested. CD206 was present on a subpopulation of untreated cells, and this sub-population was reduced after treatment. Representative dot-plots illustrating CD206-positive cells are presented in Figure 8. 


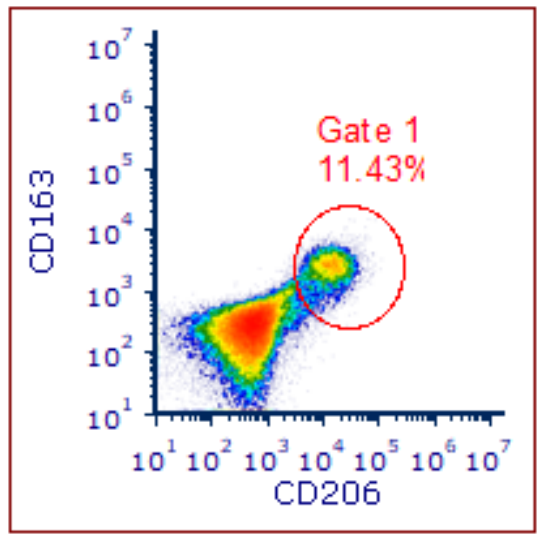

(a)

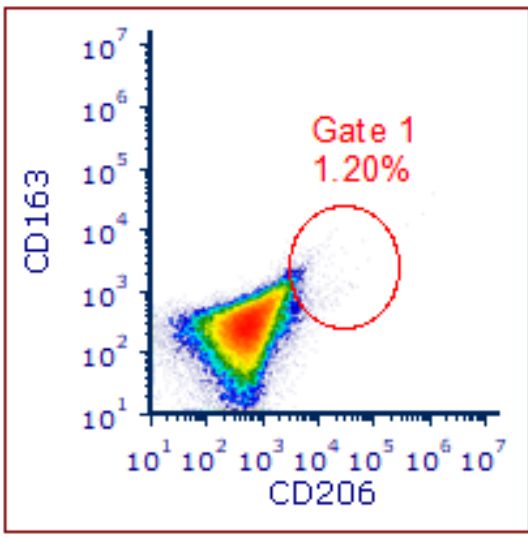

(b)

Figure 8. Expression of CD206 on adherent UCB mononuclear cells. Adherent mononuclear cells from UCB were left untreated or exposed to $1 \mu \mathrm{M}$ ATRA, $10 \mathrm{ng} / \mathrm{ml}$ IL2 and $5 \mathrm{ng} / \mathrm{ml}$ TGF $\beta$, and after 48 hours the expression of CD206 conjugated to PE/CY7 and CD163 conjugated to PE was tested in flow cytometry. Representative dot-plots showing expression of CD206 on untreated (a), and treated (b) adherent cells are presented.

In order to quantify the changes induced by exposure of UCB mononuclear cells, mean channels of fluorescence, and percentages of cells positive for CD206 antigen were calculated for the cells tested. The graphs presented in Figure 9 show the results obtained.

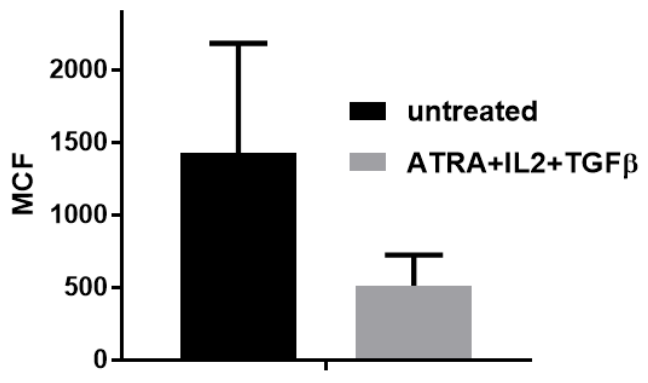

(a)

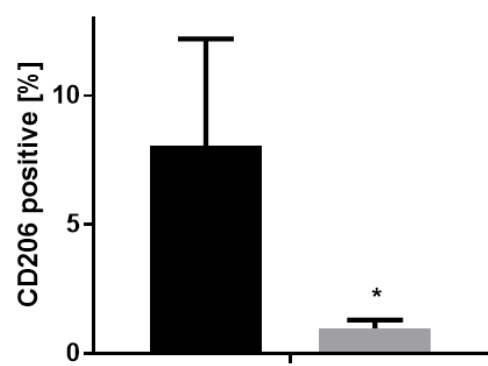

(b)

Figure 9. Expression of CD206 on UCB mononuclear cells. Mononuclear adherent cells from UCB were left untreated or exposed to $1 \mu \mathrm{M}$ ATRA, $10 \mathrm{ng} / \mathrm{ml}$ IL2 and $5 \mathrm{ng} / \mathrm{ml} \mathrm{TGF} \beta$, and after 48 hours the expression of CD206 conjugated to PE/CY7 was tested in flow cytometry. Mean channels of fluorescence (MCF) are presented in panel (a), and percents of CD206 positive cells are presented in panel (b). Value significantly different from that observed in respective untreated cells is marked with asterisk $\left({ }^{*} \mathrm{p}<0.05\right)$.

\section{Discussion}

Screenings in which gene expression arrays are tested can give a lot of information, however one should interpret the results from such arrays with caution. Experiments are performed using given exposure time, while the kinetics of expression of variable genes in the same cell type may vary. Therefore, all results obtained, should be later confirmed, preferably using different reference housekeeping gene. An array should also contain internal controls, to verify correct carry out of the experiment. In our case, the expression of CYP4A1 in HL60 cells exposed to 1,25D was an internal control, because this gene is the one most strongly regulated by 1,25D [18]. This gene encodes 24hydroxylase of $1,25 \mathrm{D}$ which is the central enzyme in the catabolism of 1,25D to inactive calcitroic acid. This way, the upregulation of CYP24A1 in response to 1,25D provides a negative feedback loop which controls the concentration of a highly active hormonal form of vitamin D. Our experiment has 
revealed 15 genes (out of 93 studied) regulated by 1,25D and 14 genes regulated by ATRA in HL60 cells. However, the list of regulated genes might be longer, since some of them might be regulated for example, at shorter time points.

For this study, we decided to address the subject of ATRA-induced upregulation of FOXP3. FoxP3 is a multidomain transcription factor essential for differentiation and function of Treg cells [38]. Different mutations of the human FOXP3 gene cause a fatal disorder characterized by immune dysregulation, polyendocrinopathy, enteropathy and X-linked inheritance (IPEX syndrome) [39]. Mutations in the FOXP3 gene lead to the dysfunction of Treg cells which manifest as autoimmunity and allergy. There are two major subsets of Treg cells: natural Tregs (nTregs) generated in thymus and inducible Tregs (iTregs) produced in peripheral immune system [40]. It has been documented that iTreg development, predominantly in the gut mucosa, depends on soluble mediators including IL-2, TGF- $\beta$ and ATRA [41]. Since FOXP3 has been believed to be T cell receptor (TCR)-controlled gene, it was surprising to find this gene upregulated 1.81 times in myeloid HL60 cells exposed to ATRA. Our experiments, presented above, have documented that when these cells were exposed to the cocktail of soluble mediators, IL-2, TGF- $\beta$ and ATRA, which are necessary to generate iTregs in gut mucosa, the upregulation was as high as 4.48 times. Similar upregulation, however to a lower extent (1.32 times), was observed also in normal myeloid cells isolated from UCB. We believe that we showed for the first time that mediators necessary to generate iTregs, are able to upregulate FOXP3 in the cells of myeloid origin. The physiological significance of this observation is unclear, and further studies are needed for full understanding. However, from the developmental point of view, it shows that signaling pathways which are used in the late stages of $\mathrm{T}$ cell differentiation, are also active in the cells of myeloid lineage. That the upregulation of FOXP3 gene is higher in HL60 cells than in normal myeloid cells might be caused by the fact that HL60 cells are inhibited in their differentiation at the early steps of myeloid pathway. The upregulation of FOXP3 expression in HL60 cells was accompanied by the changes in cells phenotype. As presented in Figure $5 b$, significant increase of CD4 antigen was observed in HL60 cells after exposure to ATRA, IL2 and TGF $\beta$. The biological role of CD4 molecules on the surface of monocytes and macrophages, other than allowing for HIV infection, is not well-defined. It has been suggested that CD4 ligation on monocytes triggers macrophage differentiation [42], however, the subset of macrophages towards which differentiation is directed should be investigated in further studies. Our results show that exposure to ATRA, IL2 and TGF $\beta$ changes also the phenotype of normal human monocytes, and that the change is not towards tumor-associated macrophages.

An interesting additional information which came from our gene expression array was about the pattern of regulation of genes connected to apoptosis. $B C L 2$ gene encoding $B c 1-2$ protein was downregulated by both 1,25D and ATRA, while $B A D$ gene encoding Bad protein was upregulated by 1,25D (Table A1). Both proteins are involved in a mitochondrial step of apoptosis, and Bcl-2 has an anti-apoptotic function, antagonized by Bad, which then becomes pro-apoptotic [33]. Therefore, the changes observed in BCL2 and BAD gene expression suggest a pro-apoptotic role of ATRA and specifically of $1,25 \mathrm{D}$. This is in agreement with some earlier observations [34], but one should remember that resistance to some pro-apoptotic signals in 1,25D-differentiated HL60 cells has also been reported [35-37].

Importantly, the observations described above might support the hypothesis that $\mathrm{T}$ cells and monocytes are closely related $[5,6]$ and not only that thymocytes retain myeloid potential, but also myeloid cells retain, at least in terms of gene regulation, some lymphoid potential.

\section{Materials and Methods}

\subsection{Cells}

HL60 and Jurkat cells were from the local cell bank at the Institute of Immunology and Experimental Therapy in Wrocław. The cells were grown in RPMI-1640 medium with $25 \mathrm{mM}$ Hepes (Biowest, Nuaillé, France), 10\% fetal bovine serum, 100 units $/ \mathrm{ml}$ penicillin, and $100 \mu \mathrm{g} / \mathrm{ml}$ 
streptomycin (Sigma-Aldrich, St. Louis, MO, USA), and maintained at standard cell culture conditions.

UCB was obtained post-delivery at the First Department of Obstetrics and Gynecology, Wrocław Medical University (Wrocław, Poland) from mothers who gave informed consent for this study. The study was accepted by the local Ethical Committee (permission No 394/2015). Cord blood was diluted with PBS (Biowest) in 1:1 ratio and carefully layered onto the equal volume of Histopaque ${ }^{\circledR}-1077$ (Sigma-Aldrich), and centrifuged at $400 \mathrm{~g}$ for $30 \mathrm{~min}$. The opaque interface containing mononuclear cells was moved to the sterile tube, and washed three times with PBS. In order to obtain adherent cells, the mononuclears were diluted in $15 \mathrm{ml}$ of fresh culture medium, plated on $10 \mathrm{~cm}$ plate for adherent cells (Eppendorf, Hamburg, Germany) and incubated for 3 hours at standard cell culture conditions $\left(37^{\circ} \mathrm{C}, 5 \% \mathrm{CO}_{2}\right)$. Then the cell suspension was carefully discarded, and adherent cells were collected by vigorous washing of the plate using a fresh culture medium. The cells were then cultured at high density $\left(15 \times 10^{6} / \mathrm{ml}\right)$.

\subsection{Chemicals and Antibodies}

1,25D was purchased from Cayman Europe (Tallinn, Estonia) and ATRA was from SigmaAldrich. The compounds were dissolved in an absolute ethanol to 1000x final concentrations, and subsequently, diluted in the culture medium to the required concentration. IL2 and TGF $\beta$ (ImmunoTools, Friesoythe, Germany) were dissolved in a sterile water and stored at $-20^{\circ} \mathrm{C} . \mathrm{CD} 11 \mathrm{~b}-$ FITC, CD14-PE, CD3-PE, CD25-APC, CD163-PE and matching unspecific IgG controls were from ImmunoTools, while CD4-FITC, CD206-PE/CY7, CD4-PE/CY7 and respective matching unspecific IgG controls were from BioLegend (San Diego, CA, USA).

\subsection{Gene expression array}

HL60 cells were exposed to $10 \mathrm{nM}$ 1,25D or $1 \mu \mathrm{M}$ ATRA or to vehicle control for 96 hours. RNA was isolated using TRI Reagent ${ }^{\circledR}$ (Sigma-Aldrich), and then the samples were digested using DNase I (RNase-Free DNase Set; Qiagen, Hilden, Germany) according to the manufacturer's instructions. RNA was further purified using RNeasy Mini Kit (Qiagen). $2 \mu \mathrm{g}$ of RNA were used for reverse transcription to cDNA which was performed using RT2 First Strand Kit (Qiagen). The entire cDNA template was used to test gene expression using RT2 Profiler ${ }^{\mathrm{TM}}$ PCR Array - Custom Human RT2

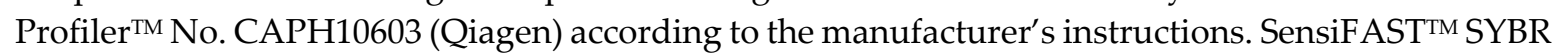
Hi-ROX from Bioline (London, UK) was used as a Real-time PCR reaction mix. StepOne ${ }^{\circledR P l u s}$ thermocycler was used to carry out reaction (Applied Biosystems, Foster City, CA, USA). The assay was repeated three times. The results were analyzed using RT2 ProfilerTM PCR Array software (www.SABioscience.com/pcrarraydataanalysis.php; accessed June 2012). Expression of $18 S$ rRNA was considered as a reference.

\subsection{Real-time PCR}

For Real-time PCR analyses, RNA from unstimulated and stimulated cells was isolated using Extractme Total RNA Kit (DNA-Gdańsk, Poland) according to the manufacturer's recommendations. Reverse transcription of $100 \mathrm{ng}$ of total RNA was performed using High-Capacity cDNA Reverse Transcription Kit (ThermoFisher Scientific, Waltham, MA, USA) using random hexamers. The Realtime PCR analysis was performed using SensiFAST SYBR ${ }^{\circledR}$ No-ROX Kit (Bioline). The reaction was performed using CFX Real-time PCR System (Bio-Rad, Hercules, CA, USA). The following primer pairs were used:

FOXP3: forward primer 5' - ACT GGT TCA CAC GCA TGT TT -3'; reverse primer 5'- GTC CAT CCT CCT TTC CTT GA - $3^{\prime}$

GAPDH: forward primer 5'- CAT GAG AAG TAT GAC AAC AGC CT -3'; reverse primer 5'- AGT CCT TCC ACG ATA CCA AAG T -3'

Relative quantification of gene expression was analyzed with the $\triangle \Delta C \mathrm{Ct}$ method [43] using GAPDH as the endogenous control. 


\subsection{Flow cytometry}

The cells were collected by vigorous washing and washed with ice-cold PBS supplemented with $0.1 \%$ BSA (PBS/BSA). The cells were incubated for $1 \mathrm{~h}$ on ice with antibodies in the amounts suggested by the producers. Then the cells were washed and suspended in $350 \mu$ of PBS/BSA prior to analysis on the Becton Dickinson Accuri C6 (San Jose, CA, USA). Data analysis was performed using Becton Dickinson Accuri C6 software.

\subsection{Statistical analysis}

All experiments were repeated from 3 to 5 times. Statistical analysis was performed using GraphPad Prism (GraphPad Software, San Diego, CA, USA). ANOVA was used to test the null hypothesis that samples in two or more groups are drawn from populations with the same mean values. When the ANOVA test had shown that the null hypothesis was not true, Student's t-test for independent samples has been used to analyze the differences between the pairs of groups, for the samples with a normal distribution. Kruskal-Wallis and Kolmogorov-Smirnov tests have been used to analyze the differences between treatment groups in the remaining samples.

Author Contributions: Conceptualization, E.M.; methodology, A.I., E.G., and E.M.; investigation, E.M., A.I., E.G. and J.Ł.; formal analysis, E.G. and E.M.; resources, E.M.; writing-original draft preparation, review and editing, E.M.; visualization, E.M.; supervision, E.M.; project administration, E.M.; funding acquisition, E.M.

Funding: Gene expression array was financed by the Project "Biotechnologies and advanced medical Technologies-BioMed" (POIG 01.01.02-02-003/08-00) financed by the European Regional Development Fund (Operational Program Innovative Economy, 1.1.2). The remaining research was supported by the National Science Centre, Poland (grant No. 2015/17/B/NZ4/02632).

Conflicts of Interest: The authors declare no conflict of interest.

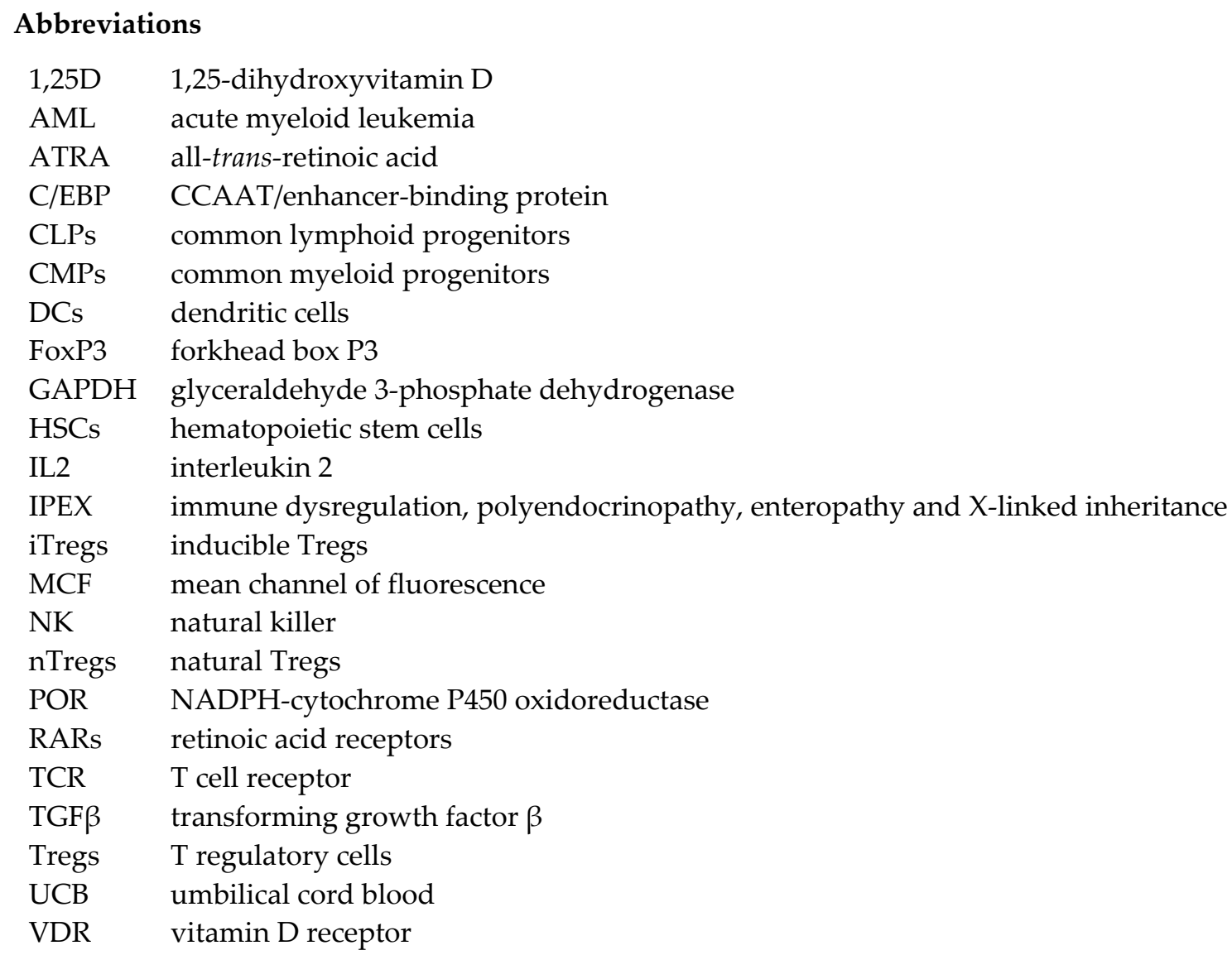




\section{Appendix A}

Table A1: Differential analysis of gene expression induced by 1,25D or ATRA in HL60 cells.

\begin{tabular}{|c|c|c|c|c|c|c|}
\hline \multirow{3}{*}{ No } & \multirow{3}{*}{ Symbol } & \multirow[b]{3}{*}{ Protein encoded } & \multirow{2}{*}{\multicolumn{2}{|c|}{$10 \mathrm{nM} 1,25 \mathrm{D}$}} & & \\
\hline & & & & & \multicolumn{2}{|c|}{$1 \mu \mathrm{M}$ ATRA } \\
\hline & & & Fold Change & $p$-value & Fold Change & p-value \\
\hline 1 & ITGAM & $\mathrm{CD} 11 \mathrm{~b}$ & 30,3493 & 0,039338 & 12,1584 & 0,036708 \\
\hline 2 & PRRG2 & PRRG2 & 1,0175 & 0,864037 & 1,3764 & 0,513682 \\
\hline 3 & ITGAL & CD11a & 1,4535 & 0,087096 & 1,578 & 0,112355 \\
\hline 4 & ITGAX & CD11c & 2,4568 & 0,231759 & 4,5873 & 0,120526 \\
\hline 5 & CD19 & CD19 & 0,987 & 0,954574 & 1,1273 & 0,796759 \\
\hline 6 & $H L A-D R A$ & HLA-DR & 1,324 & 0,535492 & 1,4007 & 0,450667 \\
\hline 7 & $H L A-D Q A 1$ & HLA-DQ & 1,2095 & 0,611916 & 1,2911 & 0,52742 \\
\hline 8 & CCR5 & CCR5 & 1,1204 & 0,586212 & 172,0969 & 0,005351 \\
\hline 9 & CXCR4 & CXCR4 & 1,4219 & 0,395401 & 0,6948 & 0,948124 \\
\hline 10 & ADGRE1 & EMR1 & 1,0868 & 0,603155 & 3,6167 & 0,01969 \\
\hline 11 & CEBPA & $\mathrm{C} / \mathrm{EBP} \alpha$ & 1,651 & 0,013245 & 0,7666 & 0,136978 \\
\hline 12 & $C E B P B$ & $\mathrm{C} / \mathrm{EBP} \beta$ & 3,1335 & 0,019984 & 3,2538 & 0,000099 \\
\hline 13 & CEBPG & $\mathrm{C} / \mathrm{EBP} \gamma$ & 0,8731 & 0,674853 & 0,7176 & 0,261658 \\
\hline 14 & CEBPE & $\mathrm{C} / \mathrm{EBP} \varepsilon$ & 1,6576 & 0,044512 & 2,2226 & 0,138174 \\
\hline 15 & $S P 1$ & SP1 & 1,3085 & 0,335414 & 1,4133 & 0,161485 \\
\hline 16 & SPI1 & PU.1 & 1,7699 & 0,027138 & 1,5247 & 0,054841 \\
\hline 17 & $E 2 F 1$ & E2F1 & 0,9434 & 0,750798 & 0,7863 & 0,345775 \\
\hline 18 & GATA1 & GATA1 & 1,2714 & 0,412467 & 1,961 & 0,13702 \\
\hline 19 & GATA2 & GATA2 & 0,3247 & 0,134379 & 0,1028 & 0,064827 \\
\hline 20 & GATA3 & GATA3 & 1,0196 & 0,845259 & 1,2089 & 0,565736 \\
\hline 21 & NOTCH1 & Notch1 & 1,1664 & 0,586384 & 1,9481 & 0,13521 \\
\hline 22 & $I K Z F 1$ & Ikaros & 1,2546 & 0,394893 & 1,257 & 0,351027 \\
\hline 23 & TCF3 & TCF 3 & 0,6925 & 0,28324 & 0,9639 & 0,983171 \\
\hline 24 & $E B F 1$ & EBF 1 & 1,0175 & 0,864037 & 1,3764 & 0,513682 \\
\hline 25 & PAX5 & Pax5 & 1,0848 & 0,667409 & 1,1375 & 0,592578 \\
\hline 26 & EGR1 & EGR1 & 0,9608 & 0,882786 & 0,9764 & 0,9795 \\
\hline 27 & EGR2 & EGR2 & 0,8491 & 0,641777 & 1,8346 & 0,743636 \\
\hline 28 & $N A B 2$ & NAB2 & 0,85 & 0,510458 & 1,2959 & 0,342355 \\
\hline 29 & GFI1 & GFI1 & 0,96 & 0,88153 & 1,7272 & 0,023885 \\
\hline 30 & $K L F 4$ & KLF4 & 1,2857 & 0,859693 & 0,4032 & 0,240222 \\
\hline 31 & IRF1 & IRF1 & 0,9027 & 0,749726 & 4,059 & 0,051685 \\
\hline 32 & $E B F 1$ & EBF1 & 1,2456 & 0,252576 & 1,1509 & 0,245362 \\
\hline 33 & FОХР3 & FoxP3 & 1,1937 & 0,206334 & 1,831 & 0,012053 \\
\hline 34 & POU5F1 & Oct-4 & 1,665 & 0,035173 & 1,8112 & 0,030774 \\
\hline 35 & MLLT3 & MLLT3 & 0,7143 & 0,333139 & 1,6218 & 0,279499 \\
\hline 36 & ZFPM1 & FOG1 & 0,484 & 0,031727 & 1,0962 & 0,622826 \\
\hline
\end{tabular}


Peer-reviewed version available at Developmental \& Comparative Immunology 2019, 96, 18-26; doi:10.1016/i.dci.2019.02.019

13 of 17

\begin{tabular}{|c|c|c|c|c|c|c|}
\hline 37 & KLF1 & KLF1 & 1,3105 & 0,097745 & 1,1556 & 0,421144 \\
\hline 38 & HEMGN & Hemogen & 1,5411 & 0,432403 & 3,5232 & 0,088604 \\
\hline 39 & $R B 1$ & $\mathrm{pRb}$ & 0,9602 & 0,987427 & 1,0942 & 0,699461 \\
\hline 40 & $V D R$ & VDR & 1,2116 & 0,537141 & 0,5117 & 0,329515 \\
\hline 41 & $R X R A$ & $\mathrm{RXR} \alpha$ & 1,0103 & 0,85438 & 0,5025 & 0,240183 \\
\hline 42 & $R X R B$ & $\mathrm{RXR} \beta$ & 1,3737 & 0,243866 & 1,7555 & 0,186042 \\
\hline 43 & $R A R A$ & RAR $\alpha$ & 1,1763 & 0,456153 & 1,6274 & 0,039075 \\
\hline 44 & $R A R B$ & RAR $\beta$ & 1,257 & 0,193103 & 1,8393 & 0,102232 \\
\hline 45 & $R A R G$ & $\mathrm{RAR} \gamma$ & 0,5309 & 0,321369 & 1,1222 & 0,74257 \\
\hline 46 & $P M L$ & PML & 1,1208 & 0,453567 & 1,3407 & 0,207421 \\
\hline 47 & FLT3 & Flt-3 & 0,1862 & 0,000398 & 1,7648 & 0,009188 \\
\hline 48 & POR & CYPOR & 1,7303 & 0,218633 & 10,8487 & 0,028503 \\
\hline 49 & CYP24A1 & CYP24A1 & 213,1347 & 0,03446 & 1,3764 & 0,513682 \\
\hline 50 & CYP27A1 & CYP27A1 & 1,0879 & 0,736676 & 6,0048 & 0,111461 \\
\hline 51 & $M P O$ & Myeloperoxidase & 1,8875 & 0,125602 & 1,3925 & 0,494191 \\
\hline 52 & $B P I$ & $\mathrm{BPI}$ & 3,6442 & 0,304598 & 10,9772 & 0,250487 \\
\hline 53 & $D E F A 3$ & Defensin $\alpha 3$ & 17,3009 & 0,274566 & 2,2479 & 0,401269 \\
\hline 54 & $E P X$ & Eosinophil peroxidase & 1,3536 & 0,03096 & 1,5474 & 0,140082 \\
\hline 55 & $L Y Z$ & Lysozyme & 13,1484 & 0,012031 & 0,8151 & 0,38908 \\
\hline 56 & LTF & Lactotransferrin & 1,0666 & 0,582623 & 0,8473 & 0,947488 \\
\hline 57 & CTSG & Cathepsin G & 5,9945 & 0,01219 & 0,4095 & 0,364102 \\
\hline 58 & CTSL1 & Cathepsin L & 1,7746 & 0,429167 & 1,3387 & 0,713271 \\
\hline 59 & CES1 & Carboxylesterase 1 & 69,6827 & 0,074734 & 1,2689 & 0,648785 \\
\hline 60 & TNF & Tumor necrosis factor & 0,2595 & 0,105664 & 0,3222 & 0,144207 \\
\hline 61 & TNFRSF1A & TNFRSF1A & 1,1569 & 0,631669 & 1,6423 & 0,357678 \\
\hline 62 & RAF1 & Raf-1 & 1,1624 & 0,492232 & 1,5657 & 0,215706 \\
\hline 63 & $M Y C$ & $\mathrm{c}-\mathrm{Myc}$ & 0,6814 & 0,178307 & 0,2408 & 0,001008 \\
\hline 64 & $M Y B$ & $\mathrm{c}-\mathrm{Myb}$ & 1,0427 & 0,968369 & 0,5902 & 0,553553 \\
\hline 65 & HRAS & h-Ras & 1,0089 & 0,96565 & 1,0737 & 0,737169 \\
\hline 66 & AKT1 & AKT1 & 1,1439 & 0,685164 & 1,2228 & 0,477458 \\
\hline 67 & TP53 & p53 & 1,0175 & 0,864037 & 1,3764 & 0,513682 \\
\hline 68 & TGFB1 & TGF $\beta$ & 1,2086 & 0,585406 & 1,1816 & 0,602025 \\
\hline 69 & TGFBR1 & TGF $\beta R 1$ & 2,4693 & 0,070073 & 1,6677 & 0,235902 \\
\hline 70 & CDKN1A & $\mathrm{p} 21^{\mathrm{CIP} 1}$ & 0,5746 & 0,420023 & 0,3702 & 0,257635 \\
\hline 71 & CDKN1B & p27KIP1 & 1,0869 & 0,533667 & 1,3058 & 0,270113 \\
\hline 72 & $C D K 1$ & CDK1 & 0,7047 & 0,091391 & 1,1189 & 0,634701 \\
\hline 73 & CDC42 & CDC42 & 1,3251 & 0,225676 & 1,5762 & 0,19262 \\
\hline 74 & PAK1 & PAK1 & 1,269 & 0,436021 & 2,7844 & 0,127753 \\
\hline 75 & BCL2 & Bcl-2 & 0,6447 & 0,032988 & 0,2083 & 0,019857 \\
\hline 76 & $B A D$ & Bad & 1,5451 & 0,041163 & 1,6015 & 0,060218 \\
\hline
\end{tabular}




\begin{tabular}{|c|c|c|c|c|c|c|}
\hline 77 & BCL2L11 & BIM & 1,7408 & 0,058323 & 1,289 & 0,483357 \\
\hline 78 & NFKB1 & NF- $\kappa B$ & 1,2657 & 0,280191 & 1,3003 & 0,438746 \\
\hline 79 & CREB1 & CREB-1 & 1,0896 & 0,596731 & 1,6446 & 0,241926 \\
\hline 80 & ELK1 & ELK1 & 1,3185 & 0,111391 & 1,9047 & 0,046814 \\
\hline 81 & GAB2 & Gab2 & 1,0705 & 0,807856 & 1,437 & 0,093542 \\
\hline 82 & STAT1 & STAT1 & 0,7839 & 0,494888 & 0,8223 & 0,518767 \\
\hline 83 & SHC1 & SHC1 & 1,6048 & 0,043312 & 1,6974 & 0,035892 \\
\hline 84 & HSP90AA1 & Hsp90 & 0,868 & 0,395571 & 1,0408 & 0,777562 \\
\hline 85 & HSPA1A & Hsp70 & 1,5337 & 0,280913 & 1,5889 & 0,232395 \\
\hline 86 & HSF1 & HSF1 & 1,2087 & 0,432827 & 0,8654 & 0,701011 \\
\hline 87 & $L R P 2$ & Megalin & 0,9475 & 0,975389 & 0,9752 & 0,790114 \\
\hline 88 & JUN & c-Jun & 1,1475 & 0,771829 & 0,3783 & 0,183958 \\
\hline 89 & FOS & c-Fos & 1,0816 & 0,742128 & 0,5767 & 0,254145 \\
\hline 90 & $H D A C 1$ & HDAC1 & 1,0057 & 0,97369 & 1,5754 & 0,295939 \\
\hline 91 & HAT1 & HAT1 & 0,8328 & 0,378472 & 0,841 & 0,643618 \\
\hline 92 & ACTB & $\beta$-actin & 1,4193 & 0,228969 & 1,9656 & 0,069986 \\
\hline 93 & $18 S$ rRNA & & 1 & 1 & 1 & 1 \\
\hline
\end{tabular}

HL60 cells were exposed to vehicle control or to $10 \mathrm{nM} 1,25 \mathrm{D}$ or $1 \mu \mathrm{M}$ ATRA for 96 hours. Then the expression of 93 genes was studied using RT2 Profiler ${ }^{\mathrm{TM}}$ PCR Array. 18S $r$ RNA was used as a reference gene and untreated cells were used as a calibrator. The assay was repeated three times. Genes whose expression was significantly upregulated in response to the treatment are marked in red, while these which were significantly downregulated are marked in blue. P values that are lower than 0.05 are marked in green.

\section{References}

1. Doulatov, S.; Notta, F.; Laurenti, E.; Dick, J., Hematopoiesis: a human perspective. Cell Stem Cell 2012, 10, (2), 120-36.

2. Ishikawa, F.; Niiro, H.; Iino, T.; Yoshida, S.; Saito, N.; Onohara, S.; Miyamoto, T.; Minagawa, H.; Fujii, S.; Shultz, L.; Harada, M.; Akashi, K., The developmental program of human dendritic cells is operated independently of conventional myeloid and lymphoid pathways. Blood 2007, 110, (10), 3591-660.

3. Wong, A.; Bunce, C.; Lord, J.; Salt, J.; Brown, G., Evidence that precursor cells of monocytes and B-lymphocytes are closely related. Exp Hematol 1989, 17, (9), 968-73.

4. Xie, H.; Ye, M.; Feng, R.; Graf, T., Stepwise reprogramming of B cells into macrophages. Cell 2004, 117, 663-76.

5. Bell, J.; Bhandoola, A., The earliest thymic progenitors for $\mathrm{T}$ cells possess myeloid lineage potential. Nature 2008, 452, 764-7.

6. Wada, H.; Masuda, K.; Satoh, R.; Kakugawa, K.; Ikawa, T.; Katsura, Y.; Kawamoto, H., Adult T-cell progenitors retain myeloid potential. Nature 2008, 452, 768-72.

7. Graf, T., Immunology: blood lines redrawn. Nature 2008, 452, (7188), 702-3. 
8. Ceredig, R.; Rolink, A.; Brown, G., Models of haematopoiesis: Seeing the wood for the trees. Nat Rev Immunol 2009, 9, 293-30.

9. Gocek, E.; Marcinkowska, E., Differentiation therapy of acute myeloid leukemia. Cancers 2011, 3, 2402-2420.

10. Marchwicka, A.; Cebrat, M.; Sampath, P.; Snieżewski, Ł.; Marcinkowska, E., Perspectives of differentiation therapies of acute myeloid leukemia: the search for the molecular basis of patients' variable responses to 1,25-dihydroxyvitamin D and vitamin D analogs. Front Oncol 2014, 4, (125).

11. Frankfurt, O.; Peterson, L.; Gallagher, R.; Tallman, M., APL: a classic tale of bench to bedside. In Acute Myelogenous Leukemia, Karp, J., Ed. Humana Press: Totowa, New Jersey, 2007; pp 193-228.

12. Aranda, A.; Pascual, A., Nuclear hormone receptors and gene expression. Physiol Rev 2001, 81, 1269-1304.

13. Janik, S.; Nowak, U.; Łaszkiewicz, A.; Satyr, A.; Majkowski, M.; Marchwicka, A.; Śnieżewski, Ł.; Berkowska, K.; Gabryś, M. C., M,; Marcinkowska, E., Diverse Regulation of Vitamin D Receptor Gene Expression by 1,25-Dihydroxyvitamin D and ATRA in Murine and Human Blood Cells at Early Stages of Their Differentiation. Int J Mol Sci 2017, 18, 1323.

14. Gocek, E.; Marchwicka, A.; Baurska, H.; Chrobak, A.; Marcinkowska, E., Opposite regulation of vitamin D receptor by ATRA in AML cells susceptible and resistant to vitamin D-induced differentiation. J Steroid Biochem Mol Biol 2012, 132, (3-5), 220-6.

15. Baurska, H.; Kiełbiński, M.; Biecek, P.; Haus, O.; Jaźwiec, B.; Kutner, A.; Marcinkowska, E., Monocytic differentiation induced by side-chain modified analogs of vitamin $\mathrm{D}$ in ex vivo cells from patients with acute myeloid leukemia. Leuk Res 2014, 38, (5), 638-47.

16. Gallagher, R.; Collins, S.; Trujillo, J.; McCredie, K.; Ahearn, M.; Tsai, S.; Metzgar, R.; Aulakh, G.; Ting, R.; Ruscetti, F.; Gallo, R., Characterization of the continuous, differentiating myeloid cell line (HL-60) from a patient with acute promyelocytic leukemia. Blood 1979, 54, 713-733.

17. Bunce, C.; Lord, J.; Wong, A.; Brown, G., Near neighbour analysis of variant cell lines derived from the promyeloid cell line HL60. Br J Cancer 1988, 57, (6), 559-63.

18. Vaisanen, S.; Dunlop, T.; Sinkkonen, L.; Frank, C.; Carlberg, C., Spatio-temporal activation of chromatin on the human CYP24 gene promoter in the presence of 1alpha,25dihydroxyvitamin D3. J Mol Biol 2005, 350, 65-77.

19. Zheng, Y.; Rudensky, A., Foxp3 in control of the regulatory T cell lineage. Nat Immunol 2007, 8, (5), 457-62.

20. Baurska, H.; Kłopot, A.; Kiełbiński, M.; Chrobak, A.; Wijas, E.; Kutner, A.; Marcinkowska, E., Structure-function analysis of vitamin $\mathrm{D}_{2}$ analogs as potential inducers of leukemia differentiation and inhibitors of prostate cancer proliferation. J Steroid Biochem Mol Biol 2011, 126, 46-54.

21. Gocek, E.; Marchwicka, A.; Bujko, K.; Marcinkowska, E., NADPH-cytochrome p450 reductase is regulated by all-trans retinoic acid and by 1,25-dihydroxyvitamin $\mathrm{D}_{3}$ in human acute myeloid leukemia cells. PLoS One 2014, 9, (3), e91752.

22. Friedman, A., Transcriptional control of granulocyte and monocyte development. Oncogene 2007, 26, 6816-28. 
23. Marchwicka, A.; Marcinkowska, E., Regulation of Expression of CEBP Genes by Variably Expressed Vitamin D Receptor and Retinoic Acid Receptor $\alpha$ in Human Acute Myeloid Leukemia Cell Lines. Int J Mol Sci 2018 19, (7), 1918.

24. Springer, T., Adhesion receptors of the immune system. Nature 1990 346, (6283), 425-34.

25. Ragland, S.; Criss, A., From bacterial killing to immune modulation: Recent insights into the functions of lysozyme. PLoS Pathog 2017, 13, (9), e1006512.

26. Schneider, U.; Schwenk, H.; Bornkamm, G., Characterization of EBV-genome negative "null" and " $\mathrm{T}$ " cell lines derived from children with acute lymphoblastic leukemia and leukemic transformed non-Hodgkin lymphoma. Int J Cancer 1977, 19, (5), 621-6.

27. Dominguez-Villar, M.; Fernandez-Ponce, C.; Munoz-Suano, A.; Gomez, E.; RodríguezIglesias, M.; Garcia-Cozar, F., Up-regulation of FOXP3 and induction of suppressive function in CD4+ Jurkat T-cells expressing hepatitis C virus core protein. Clin Sci (Lond) 2012.

28. Schmidt, A.; Eriksson, M.; Shang, M.; Weyd, H.; Tegnér, J., Comparative Analysis of Protocols to Induce Human CD4+Foxp3+ Regulatory T Cells by Combinations of IL-2, TGFbeta, Retinoic Acid, Rapamycin and Butyrate. PLoS One 2016, 11, (2), e0148474.

29. Zhao, H.; Liao, X.; Kang, Y., Tregs: Where We Are and What Comes Next? Front Immunol 2017, 8, 1578.

30. Ahlmann, M.; Hempel, G., The effect of cyclophosphamide on the immune system: implications for clinical cancer therapy. Cancer Chemother Pharmacol 2016, 78, (4), 661-71.

31. Wahl, L.; Wahl, S.; Smythies, L.; Smith, P., Isolation of human monocyte populations. In Curr Protoc Immunol, 2006; p 7.6A.

32. Rőszer, T., Understanding the Mysterious M2 Macrophage through Activation Markers and Effector Mechanisms. Mediators Inflamm 2015, 2015, 816460.

33. Zinkel, S.; Gross, A.; Yang, E., BCL2 family in DNA damage and cell cycle control. Cell Death Differ 2006, 13, (8), 1351-9.

34. Harrison, J.; Wang, X.; Studzinski, G., The role of VDR and BIM in potentiation of cytarabineinduced cell death in human AML blasts. Oncotarget 2016, 7, (24), 36447-36460.

35. Wang, X.; Studzinski, G., Antiapoptotic action of 1,25-dihydroxyvitamin $\mathrm{D}_{3}$ is associated with increased mitochondrial MCL-1 and RAF-1 proteins and reduced release of cytochrome c. Exp Cell Res 1997, 235, (1), 210-7.

36. Marcinkowska, E.; Chrobak, A.; Wiedlocha, A., Evading apoptosis by calcitriol-differentiated human leukemic HL-60 cells is not mediated by changes in CD95 receptor system but by increased sensitivity of these cells to insulin. Exp Cell Res 2001, 270, (1), 119-27.

37. Mosieniak, G.; Śliwińska, M.; Piwocka, K.; Sikora, E., Curcumin abolishes apoptosis resistance of calcitriol-differentiated HL-60 cells. FEBS Lett 2006, 580, (19), 4653-60.

38. Josefowicz, S.; Lu, L.; Rudensky, A., Regulatory T cells: mechanisms of differentiation and function. Annu Rev Immunol 2012, 30, 531-64.

39. Bennett, C.; Christie, J.; Ramsdell, F.; Brunkow, M.; Ferguson, P.; Whitesell, L.; Kelly, T.; Saulsbury, F.; Chance, P.; Ochs, H., The immune dysregulation, polyendocrinopathy, enteropathy, X-linked syndrome (IPEX) is caused by mutations of FOXP3. Nat Genet 2001, 27, (1), 20-1.

40. Thompson, C.; Powrie, F., Regulatory T cells. Curr Opin Pharmacol 2004, 4, (4), 408-14. 
41. Hall, J.; Grainger, J.; Spencer, S.; Belkaid, Y., The role of retinoic acid in tolerance and immunity. Immunity 2011, 35, (1), 13-22.

42. Zhen, A.; Krutzik, S.; Levin, B.; Kasparian, S.; Zack, J.; Kitchen, S., CD4 ligation on human blood monocytes triggers macrophage differentiation and enhances HIV infection. J Virol 2014, 88, (17), 9934-46.

43. Livak, K.; Schmittgen, T., Analysis of relative gene expression data using real-time quantitative PCR and the $2^{\wedge}[$-delta delta $C(T)]$ method. Methods 2001, 25, 402-8. 